\title{
INFLUÊNCIA DAS TEMPERATURAS DE RECOZIMENTO CONTÍNUO NA MICROESTRUTURA E NAS PROPRIEDADES MECÂNICAS DE AÇO BIFÁSICO (DP980) GALVANIZADO*
}

\author{
Edney Amaral Moraes ${ }^{1}$ \\ Fernando Souza Costa ${ }^{2}$ \\ Roberta de Oliveira Rocha ${ }^{3}$ \\ Dagoberto Brandão Santos ${ }^{4}$
}

\section{Resumo}

Os aços bifásicos são fortemente dependentes da microestrutura obtida para atender às necessidades na sua aplicação e as propriedades mecânicas requeridas. O processo de recozimento contínuo intercrítico afeta diretamente a formação microestrutural e por consequência as propriedades mecânicas. Nesse trabalho avaliou-se a influência das temperaturas de encharque intercrítico e de fim de resfriamento lento na microestrutura e nas propriedades mecânicas de um aço laminado a frio e revestido da classe de $980 \mathrm{MPa}$ a partir de simulação via simulador termomecânico Gleeble. Análises via microscopia eletrônica de varredura revelaram aumento da fração de segundo constituinte com o aumento da temperatura de encharque, fato associado à formação de maiores frações de austenita durante recozimento intercrítico, refletindo no aumento do limite de escoamento e limite de resistência. A microestrutura e as propriedades mecânicas não apresentaram alteração com a variação da temperatura de fim de resfriamento lento.

Palavras-chave: Aços bifásicos; Recozimento contínuo; Propriedades mecânicas.

\section{INFLUENCE OF TEMPERATURE OF CONTINUOUS ANNEALING ON THE MICROSTRUCTURE AND MECHANICAL PROPERTIES OF GALVANIZED DUAL PHASE STEEL (DP980)}

\begin{abstract}
Dual phase steels are strongly dependent on the microstructure obtained to meet the needs in its application and the required mechanical properties. The process of continuous intercritical annealing directly affects the microstructure formation and consequently the mechanical properties. In this study, the influence of intercritical soaking temperature and slow cooling temperature on microstructure and mechanical properties of a cold-rolled steel and coated $980 \mathrm{MPa}$ class from simulation on a thermomechanical simulator Gleeble were evaluated. Analysis via scanning electron microscopy revealed increased in the volume fraction of second phase with increasing soaking temperature, indeed associated with the formation of larger volume fraction of austenite during intercritical annealing, reflecting the increase in yield strength and tensile strength. The microstructure and mechanical properties did not change with the variation of end of slow cooling temperature.

Keywords: Dual phase steels; Continuous annealing; Mechanical properties.

\footnotetext{
Engenheiro Metalurgista, Controle Integrado do Produto da Usiminas, Ipatinga, MG, Brasil.

Físico, Centro de Tecnologia da Usiminas, Ipatinga, MG, Brasil.

Engenheira Metalurgista, Controle Integrado do Produto da Usiminas, Ipatinga, MG, Brasil.
}

Engenheiro Metalurgista, Eng. Metalúrgica e de Materiais, UFMG, Belo Horizonte, MG, Brasil.
\end{abstract}




\section{INTRODUÇÃO}

Ao se discutir os aços de alta resistência ou mais especificamente os aços avançados de alta resistência, também conhecidos pela sigla AHSS - Advanced High Strength Steels, não há como deixar de descrever os desafios relacionados à redução do peso do veículo e aumento da segurança dos passageiros estabelecidos para indústria automobilística. Por um período esses dois temas foram tratados como sendo incompatíveis, uma vez que a redução da espessura poderia reduzir a segurança veicular em um possível impacto, porém com advento de novas tecnologias de produção de aços, assim como o entendimento e utilização de elementos de ligas, é possível reduzir a espessura dos componentes veiculares mantendo ou aumentando a segurança dos passageiros.

Dentre os aços AHSS destaca-se o bifásico ou dual phase (DP) constituído basicamente por uma matriz ferrítica e um segundo constituinte, geralmente a martensita. Bainita e austenita retida também podem ser observadas em alguns casos. A ferrita favorece a ductilidade e a martensita é a principal responsável pela alta resistência. A combinação desses dois constituintes propicia um aço com elevada resistência mecânica, associada a uma ductilidade adequada.

De forma geral, a formação de aços com estrutura bifásica a partir do processo de recozimento contínuo à temperatura intercrítica envolve as seguintes transformações: recristalização da ferrita, dissolução da perlita, formação da austenita durante as etapas de aquecimento e encharque e sua decomposição durante resfriamento.

A formação da austenita durante o recozimento intercrítico tem efeito direto na microestrutura final e por sua vez nas propriedades mecânicas obtidas no aço [1]. Isso porque a microestrutura e as propriedades mecânicas são dependentes da fração volumétrica, morfologia e distribuição dos constituintes microestruturais, que por sua vez são influenciados pela quantidade, morfologia e distribuição da austenita formada durante o recozimento intercrítico.

De acordo com a literatura [2-5], quanto maior a temperatura de encharque maior a fração de austenita no recozimento intercrítico, porém quanto maior a quantidade de austenita menor será sua concentração de carbono e de elementos de liga e menor será sua temperabilidade. A menor temperabilidade facilitará a formação de grande quantidade de nova ferrita ou bainita em substituição à martensita na estrutura final, isso pode acarretar na redução da resistência do aço.

Contudo observou na revisão sobre aços bifásicos [6] e em outros trabalhos [7,8] que a resistência do aço aumentou com o aumento da temperatura de recozimento intercrítico.

Nesse trabalho objetivou-se estudar a influência de diferentes condições de processo do recozimento contínuo nas propriedades mecânicas de aços bifásicos galvanizados a quente, revestimento galvannealed (GA), da classe de $980 \mathrm{MPa}$ de limite de resistência mínimo (DP980), por meio de simulações de recozimento contínuo, caracterização metalográfica e avaliação mecânica.

\section{MATERIAIS E MÉTODOS}

O estudo foi desenvolvido a partir de amostras com espessura de 1,20 mm; obtidas industrialmente após o processo de laminação a frio. Foram retiradas amostras de $150 \mathrm{~mm}$ x $50 \mathrm{~mm}$ para a simulação do recozimento intercrítico via máquina Gleeble modelo 3500. A composição química do aço estudado é mostrada na tabela 1. 
Tabela 1. Composição química do aço (\% em peso)

\begin{tabular}{cccccc}
\hline $\mathrm{C}$ & $\mathrm{Si}$ & $\mathrm{Mn}$ & $\mathrm{Ti}+\mathrm{Nb}$ & $\mathrm{Cr}+\mathrm{Mo}$ & $\mathrm{B}$ \\
\hline 0,06 a 0,15 & 0,10 a 0,50 & 1,50 a 2,50 & $\leq 0,050$ & $\leq 0,70$ & 0,0010 a 0,0050 \\
\hline
\end{tabular}

A figura 1 mostra o esquema do ciclo completo de recozimento intercrítico que foi simulado via Gleeble. As simulações foram realizadas com base nas dimensões da linha de Galvanização Contínua ${ }^{\circ} 2$ da Usiminas. Para esse equipamento definiu-se o tempo de permanência em cada etapa em função da velocidade e comprimento de cada região.

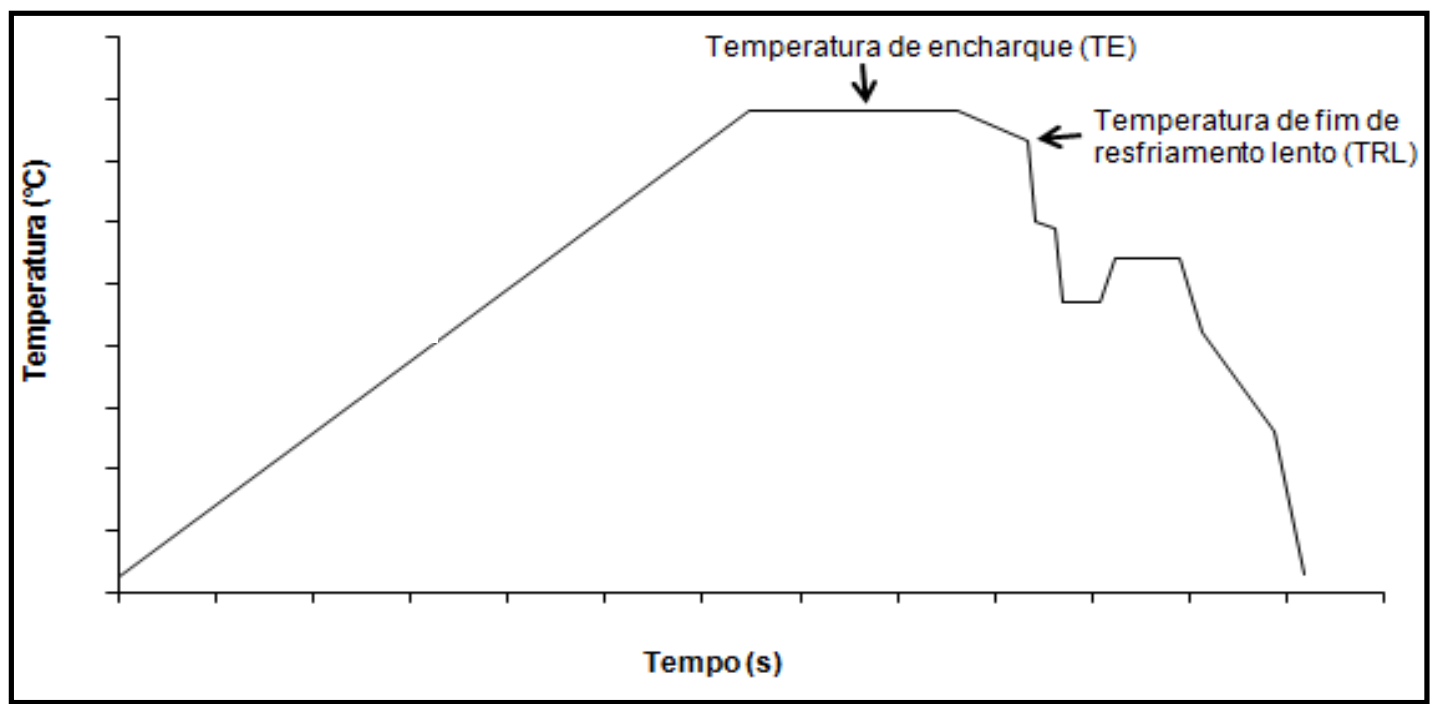

Figura 1. Representação esquemática dos ciclos de recozimento intercrítico e galvannealed simulados via Gleeble.

Nesse trabalho se planejou avaliar o efeito da variação de dois parâmetros de recozimento intercrítico sob a microestrutura e propriedades mecânicas de um aço DP980, a saber: temperatura de encharque (TE) e temperatura de fim de resfriamento lento (TRL). Foram avaliadas cinco temperaturas de encharque, $720^{\circ} \mathrm{C}$, $750^{\circ} \mathrm{C}, 780^{\circ} \mathrm{C}, 810^{\circ} \mathrm{C}$, e $840^{\circ} \mathrm{C}$, fixando a temperatura de fim de resfriamento lento em $670^{\circ} \mathrm{C}$. Posteriormente, para a temperatura de encharque de $780^{\circ} \mathrm{C}$ foram testadas cinco temperaturas de fim de resfriamento lento, $610^{\circ} \mathrm{C}, 640^{\circ} \mathrm{C}, 670^{\circ} \mathrm{C}$, $700^{\circ} \mathrm{C}$ e $730^{\circ} \mathrm{C}$. Os testes dos ciclos completos de recozimento foram conduzidos simulando uma velocidade de processamento da tira de $80 \mathrm{~m} / \mathrm{min}$. Os demais parâmetros foram mantidos e controlados.

A microestrutura das amostras foi caracterizada via microscopia eletrônica de varredura (MEV), após a aplicação do reativo nital $4 \%$. As análises metalográficas foram realizadas em seção longitudinal, definida pelas direções de laminação e normal à superfície,

Com o objetivo de medir a fração volumétrica dos constituintes presentes foram gerados, para cada amostra, 20 campos de imagens via MEV com 8.000x de ampliação, sendo sobre elas justaposta uma malha retangular constituída de 165 nós. A opção pelo uso da contagem por pontos, ao invés de metodologias convencionais de análise de imagens associada à microscopia óptica, se justifica por sua elevada precisão, principalmente quando se considera o grau de refinamento e de homogeneidade da microestrutura das amostras.

Cada amostra utilizada na simulação do ciclo completo na Gleeble deu origem a três 
corpos de prova (CP) para os testes de tração preparados conforme norma ASTM A370, tamanho reduzido. Foram medidos os valores de limite de escoamento, limite de resistência, alongamento total e uniforme e expoente de encruamento (n) em CPs orientados segundo a direção perpendicular à de laminação. A velocidade dos ensaios foi de $5 \mathrm{~mm} / \mathrm{min}$. Todos os equipamentos utilizados são do Centro de Tecnologia da Usiminas.

\section{RESULTADOS E DISCUSSÃO}

A microestrutura do aço na condição de laminado a quente e a frio pode ser observada na figura 2. Observa-se a presença de ferrita, perlita, bainita e martensita.

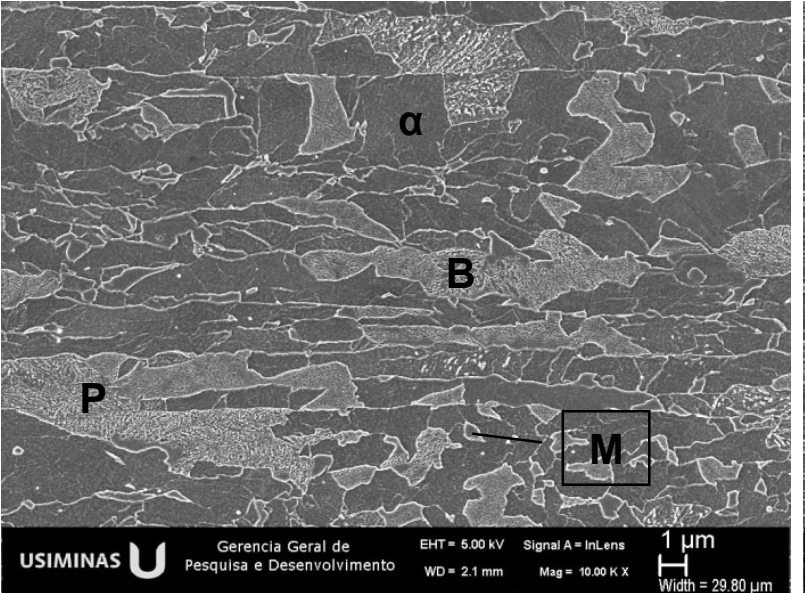

(a)

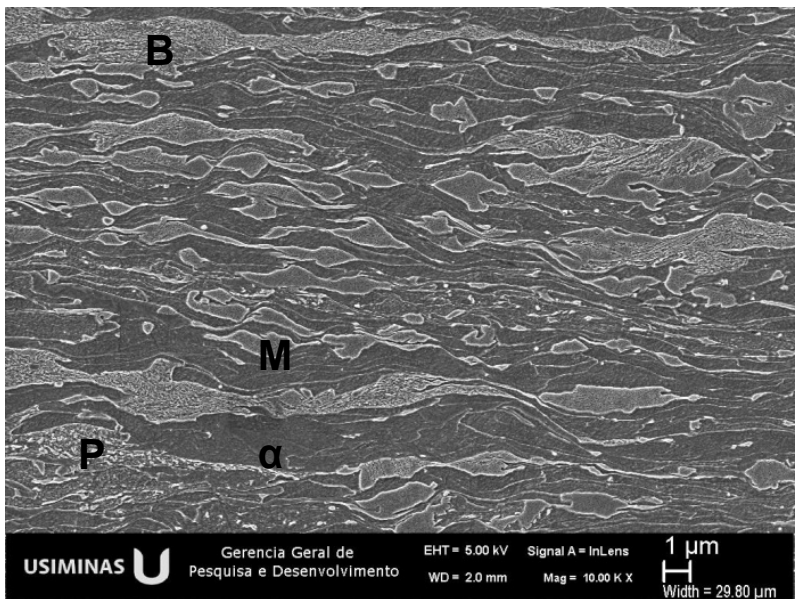

(b)

Figura 2. Microestrutura via MEV do aço DP980 após laminação industrial a quente (a) e a frio (b). $\mathrm{B}=$ bainita, $\mathrm{P}=$ perlita, $\mathrm{M}=$ martensita, $\alpha=$ ferrita. Ataque nital $4 \%$.

\subsection{Efeito da Temperatura de Encharque (TE) na Microestrutura e nas Propriedades Mecânicas}

A partir das simulações do ciclo completo observa-se o aumento dos valores de limite de escoamento (LE) e limite de resistência (LR) com o aumento da temperatura de encharque, figura 3.

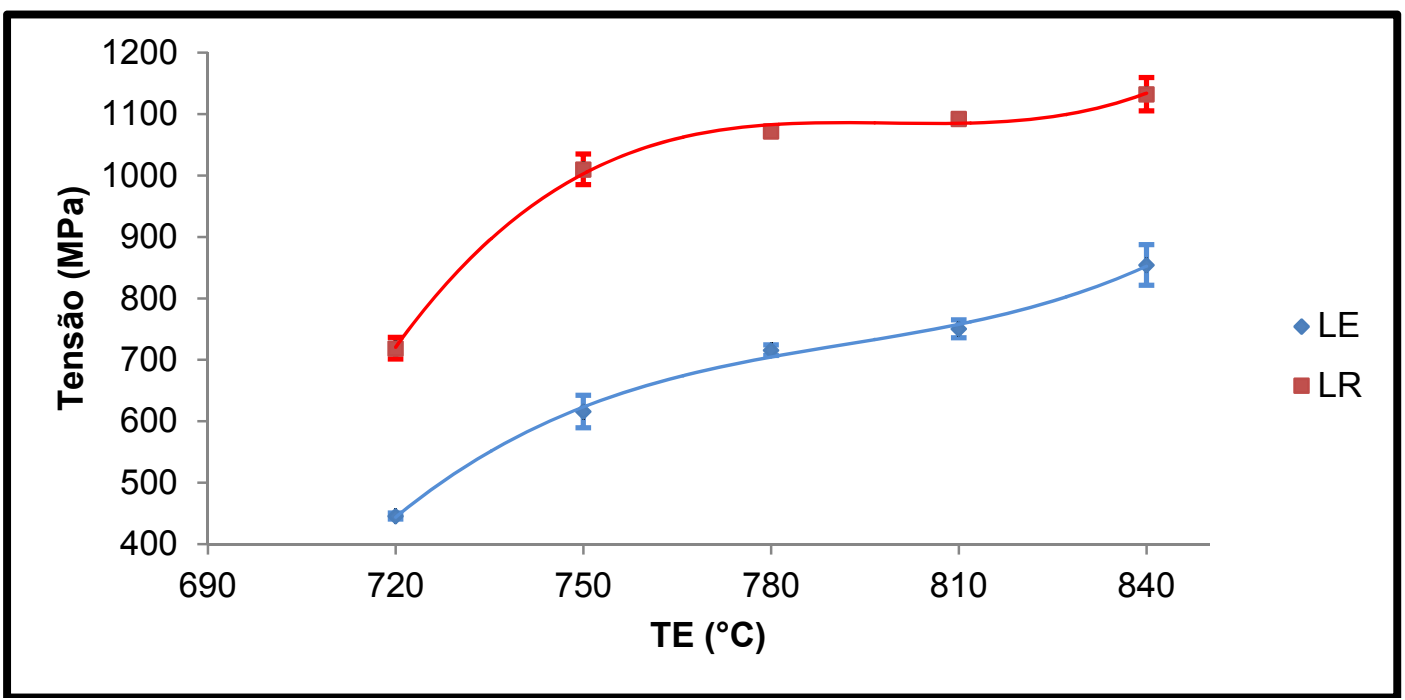

Figura 3. Variação do LE e LR em função da temperatura de encharque. 
O aumento da temperatura de encharque promoveu o aumento da fração de austenita, elevando-se assim a fração de segundo constituinte, martensita e bainita principalmente. Com isso tem-se o aumento do LE e LR. Resultados similares foram observados por Llewellyn e Hills [6] e em trabalhos recentes [7,8]. Apesar da dispersão dos dados, observou-se a tendência de redução do alongamento total e alongamento uniforme com o aumento da TE, figura 4. No trabalho de Cho et al. [9] foi verificado comportamento similar, com a redução do alongamento total diante do aumento da fração de martensita e bainita. O expoente de encruamento seguiu a mesma tendência. A figura 5 mostra o aumento da fração de segundo constituinte em detrimento da ferrita com o aumento da TE.

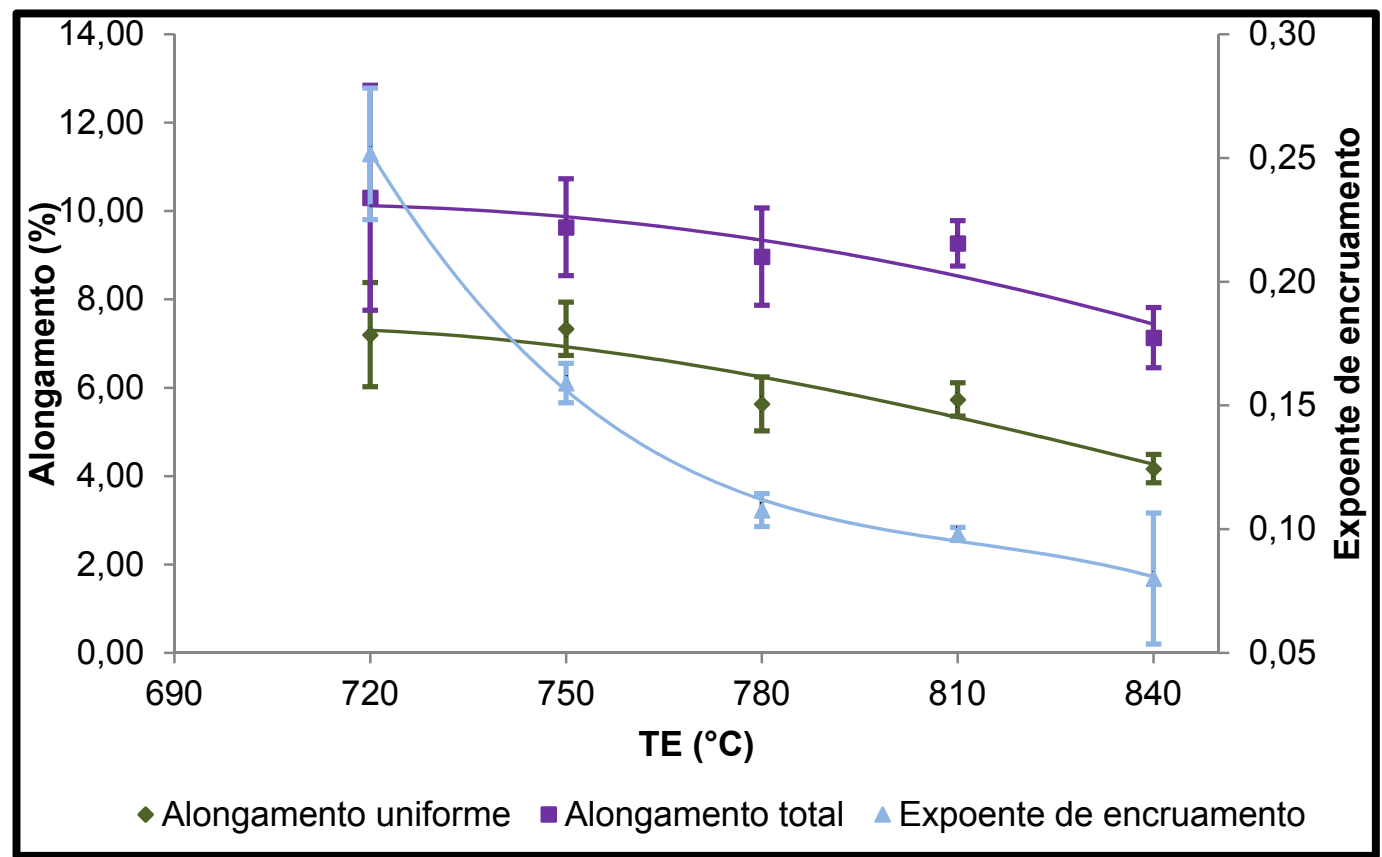

Figura 4. Variação do alongamento e expoente de encruamento em função da temperatura de encharque.

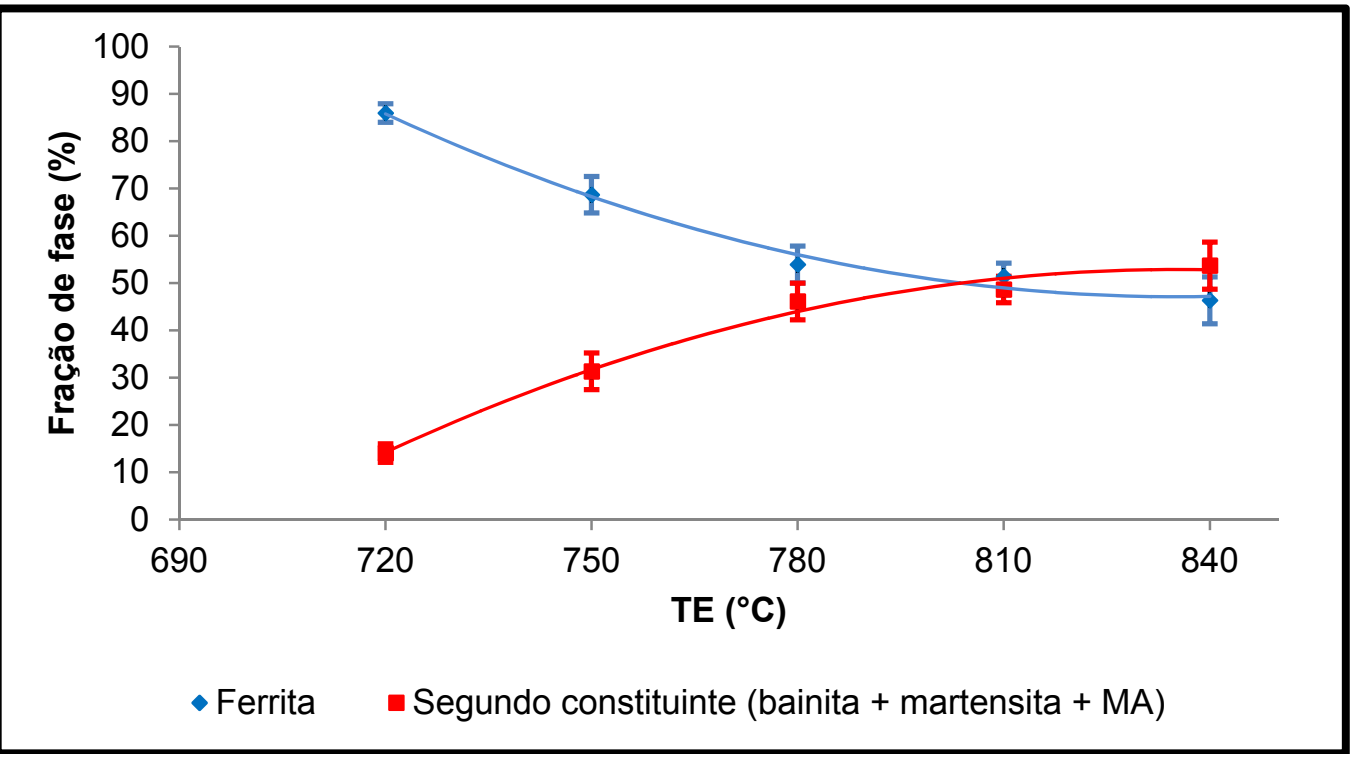

Figura 5. Efeito da temperatura de encharque na fração de ferrita e segundo constituinte (bainita + martensita + constituinte MA). 
A figura 6 mostra as microestruturas obtidas para cada temperatura de recozimento estudada. Na figura $6(\mathrm{a})$, temperatura de encharque de $720^{\circ} \mathrm{C}$, observou-se a presença de carbonetos não dissolvidos, para a temperatura de $750^{\circ} \mathrm{C}$ grande parte já se encontra dissolvida, e a partir de $780^{\circ} \mathrm{C}$, figura $6(\mathrm{c})$, não se observou a presença de carbonetos não dissolvidos na condição avaliada. Essa dissolução favorece o aumento do teor de carbono na austenita, aumentando com isso a dureza da martensita, o que resulta em aumento da resistência mecânica, fato também observado por Garcia e colaboradores [10].
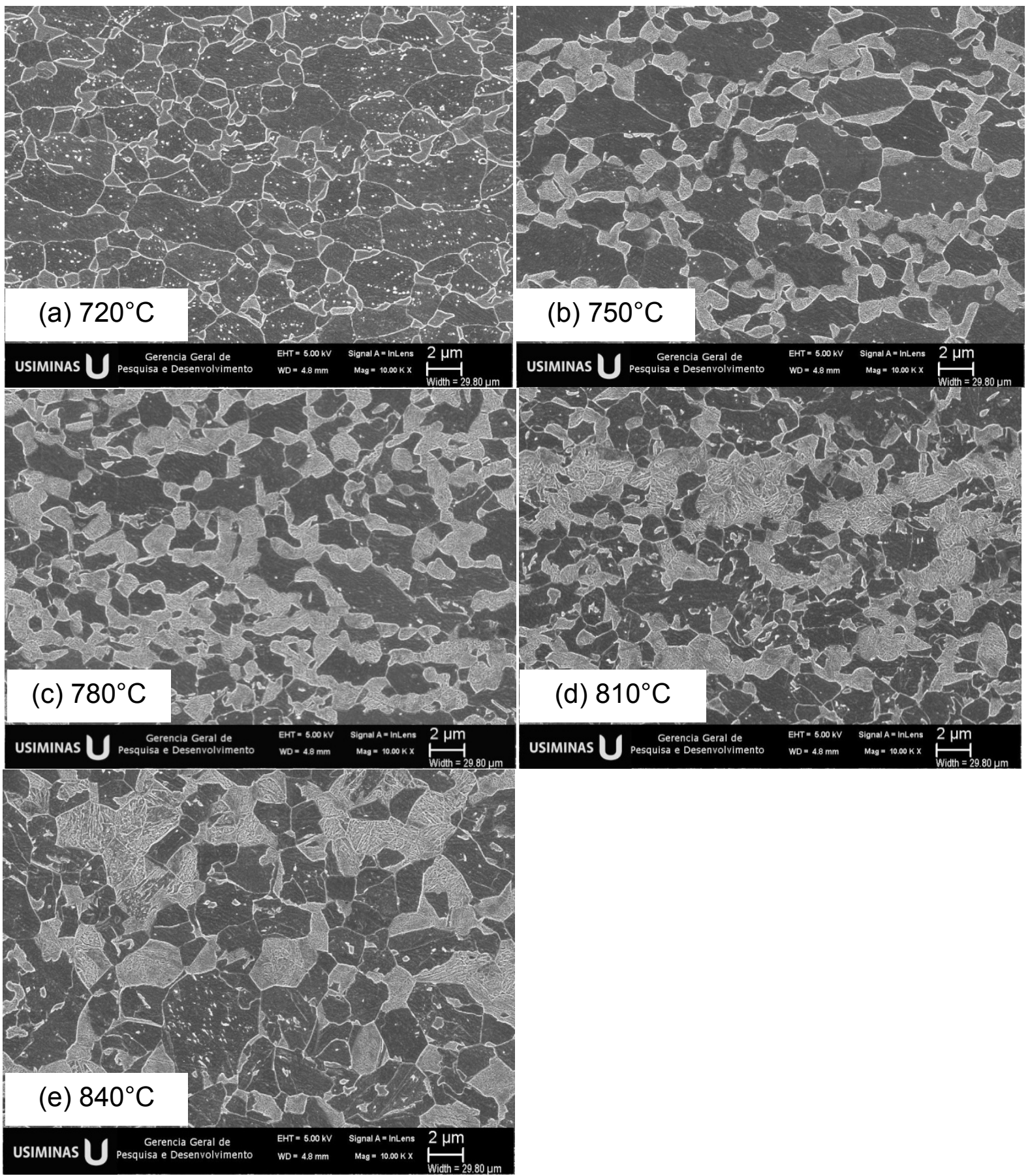

Figura 6. Microestruturas via MEV após ciclo completo variando a temperatura de encharque, ataque Nital $4 \%$. 


\subsection{Efeito da Temperatura de Fim de Resfriamento Lento (TRL) na Microestrutura e nas Propriedades Mecânicas}

Não foi observada uma tendência na variação das propriedades mecânicas em função das temperaturas de fim de resfriamento lento (TRL) testadas, mantendo-se constante a temperatura de encharque em $780^{\circ} \mathrm{C}$. Fato confirmado com a avaliação das microestruturas obtidas, que não apresentaram variações significativas das frações das fases presentes. As figuras 7 e 8 mostram a variação do LE, LR, alongamento e expoente de encruamento com a TRL. Para a TRL de $610^{\circ} \mathrm{C}$ observou-se que $o$ alongamento é pouco superior às demais temperaturas. A figura 9 mostra as microestruturas obtidas para cada temperatura.

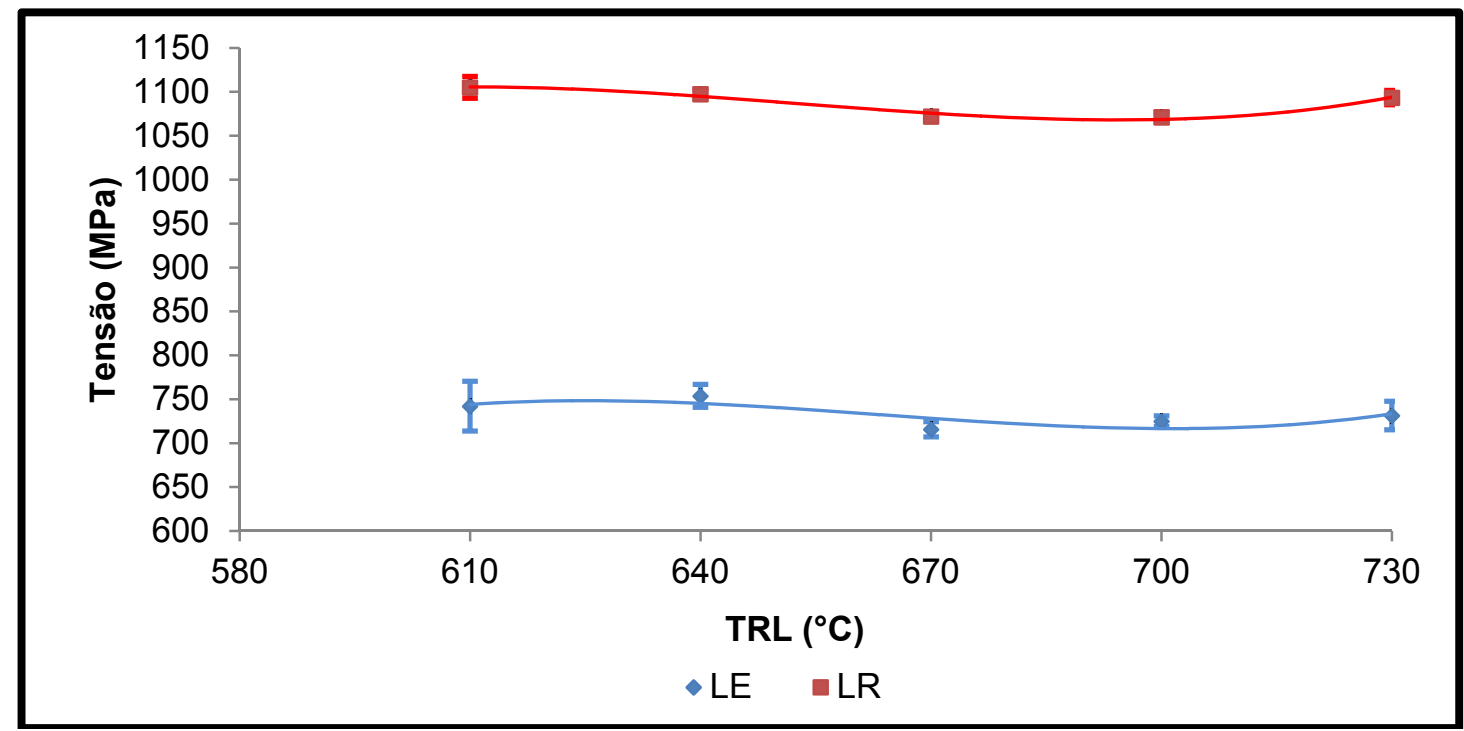

Figura 7. Variação do LE e LR em função da temperatura de fim de resfriamento lento (TRL).

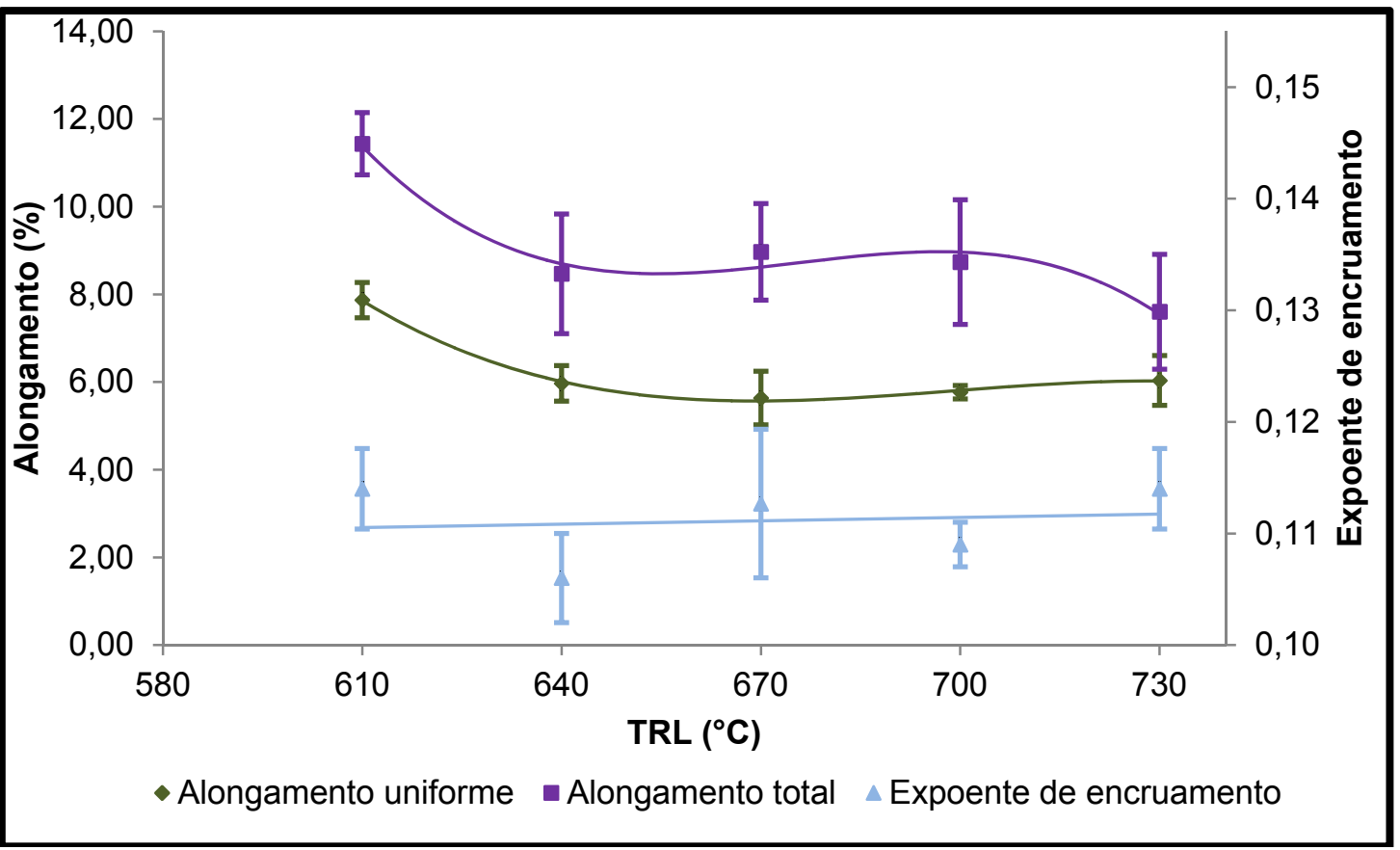

Figura 8. Variação do alongamento e do expoente de encruamento em função da temperatura de fim do resfriamento lento (TRL). 

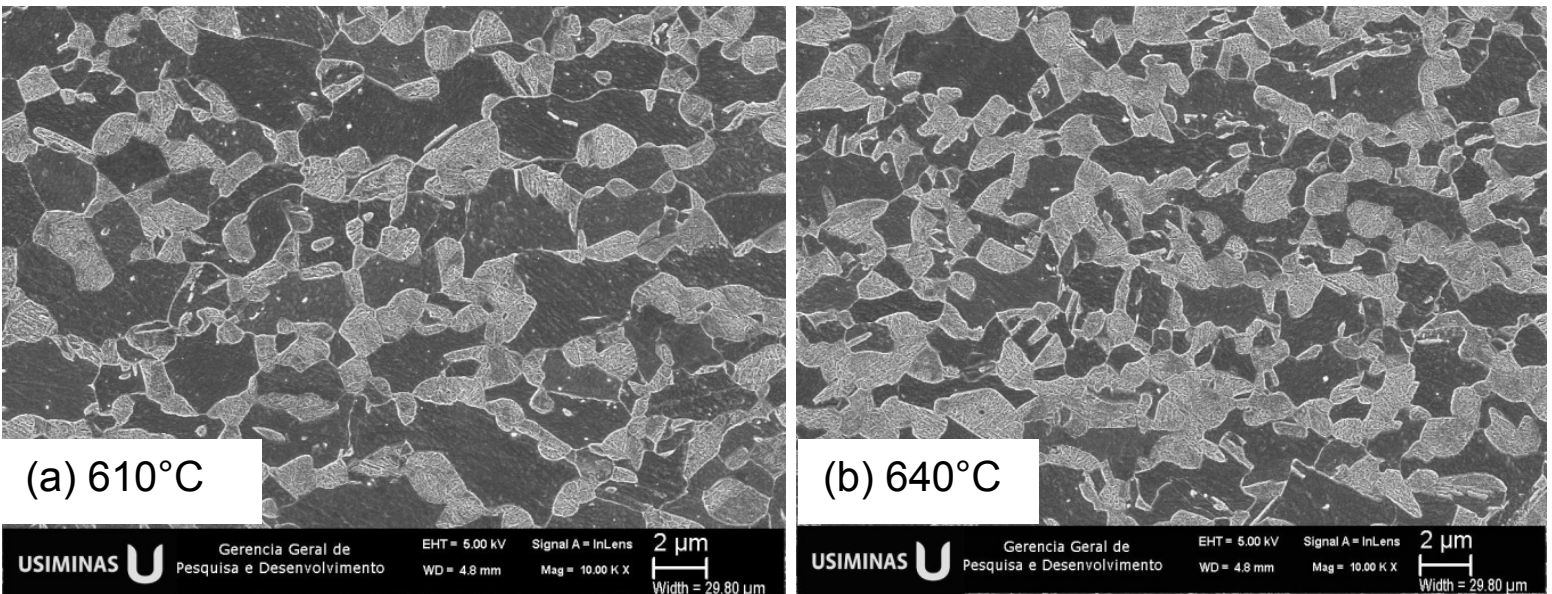

(b) $640^{\circ} \mathrm{C}$

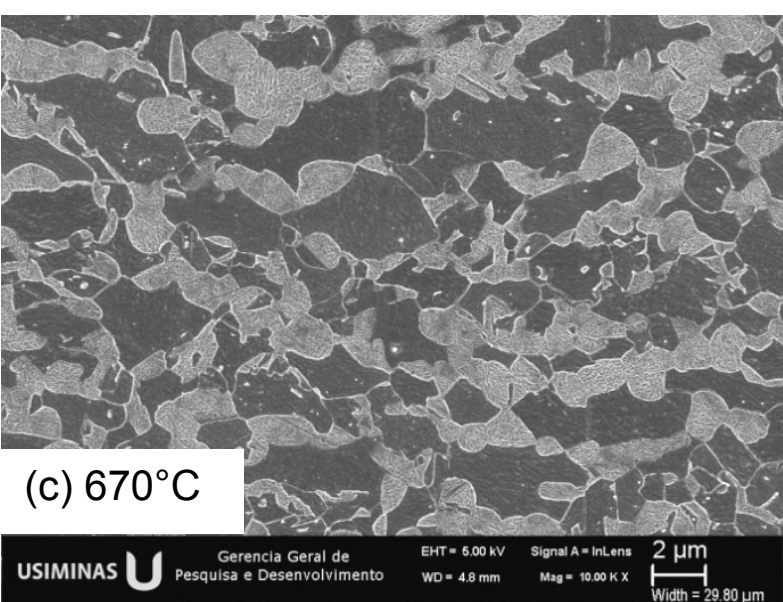

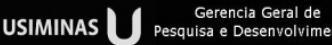
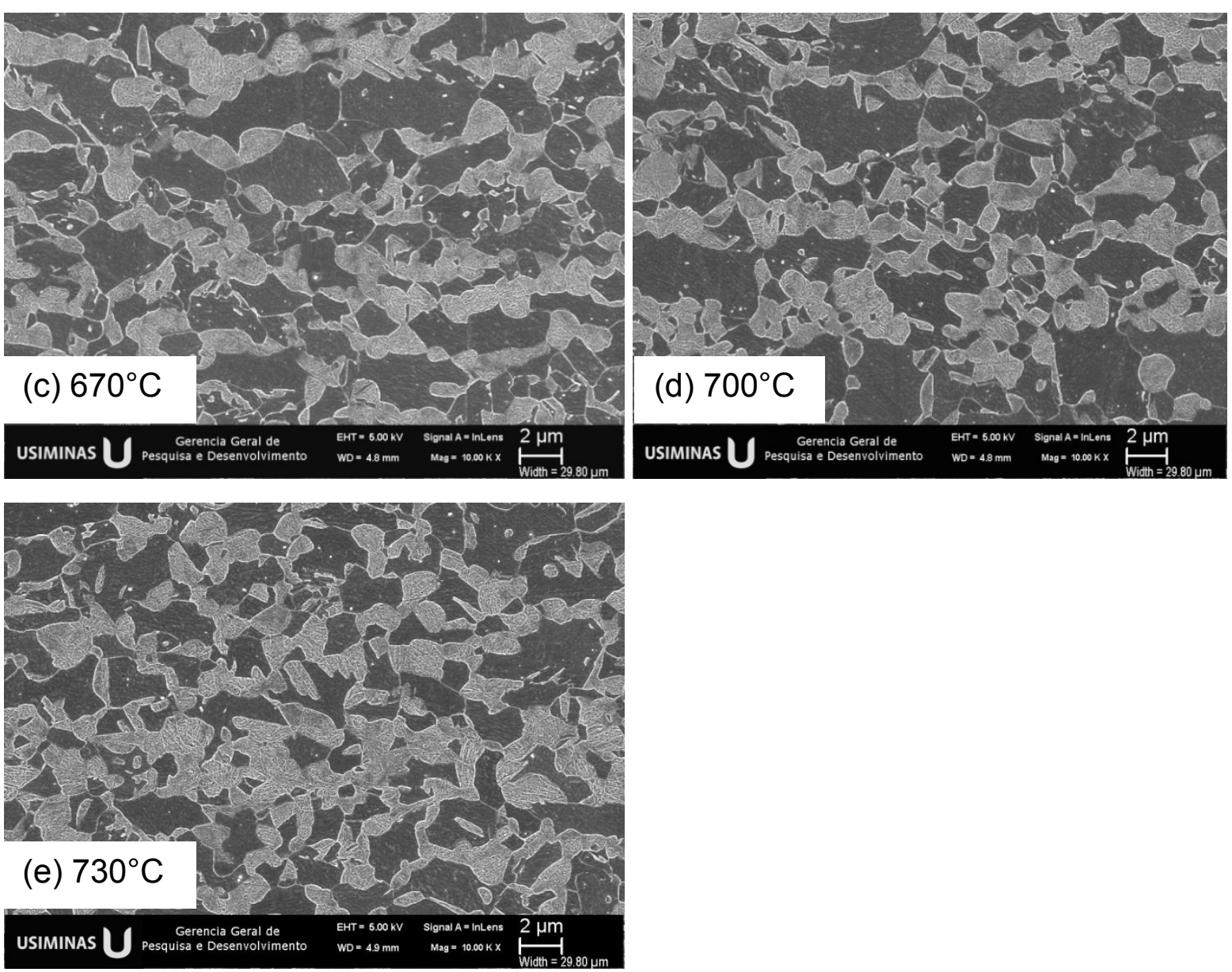

Figura 9. Microestruturas via MEV após ciclo completo variando a temperatura de fim de resfriamento lento em (a) $610^{\circ} \mathrm{C}$, (b) $640^{\circ} \mathrm{C}$, (c) $670^{\circ} \mathrm{C}$, (d) $700^{\circ} \mathrm{C}$ e (e) $730^{\circ} \mathrm{C}$, ataque Nital $4 \%$.

A figura 10 evidencia a pouca variação da fração de ferrita e segundo constituinte (bainita + martensita + MA) com variação das temperaturas de fim de resfriamento lento. Também foi observado nos trabalhos de Kuang et al. [8] e Pichler et al. [11] que o aumento da TRL favoreceu o aumento da resistência mecânica dos aços bifásicos estudados devido a formação de uma maior fração de segundo constituinte. Logo após a etapa de encharque, ao reduzir a temperatura com baixa taxa de resfriamento para valores próximos a $A c_{1}$, ocorre a transformação de parte da austenita em nova ferrita. A difusão de carbono, que ocorre durante o resfriamento, se dá em sentido contrário ao avanço da reação, provocando 
enriquecimento de sua concentração na austenita não transformada e, com isso, favorecendo o aumento da dureza da martensita obtida. Essa maior dureza da martensita promove o aumento da resistência mecânica do aço.

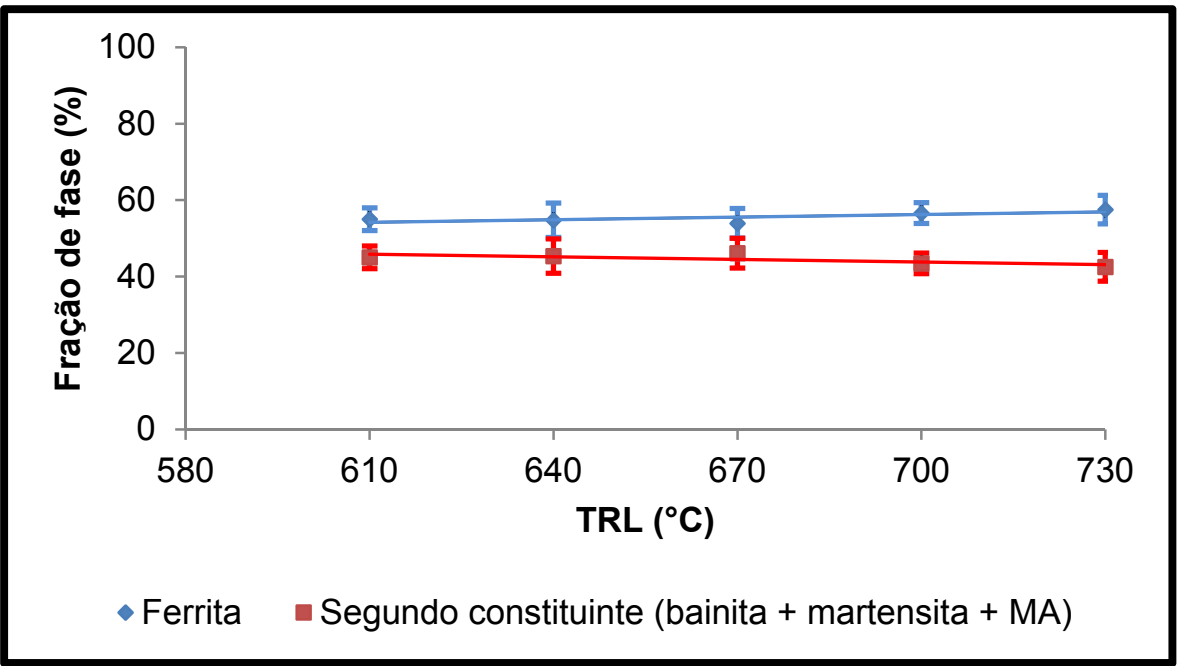

Figura 10. Efeito da temperatura de fim de resfriamento lento na fração de ferrita e segundo constituinte (bainita + martensita + constituinte MA).

No aço estudado nesse trabalho observou-se pouca formação de nova ferrita. Com isso houve pouca variação do teor de carbono na austenita não transformada na etapa de resfriamento lento. Isso justifica a pouca variação dos valores de LE, LR e também da fração de segundo constituinte em função da temperatura de fim de resfriamento lento. A partir do mecanismo de formação da nova ferrita, baseado no crescimento por epitaxia a partir da ferrita existente e das interfaces austenita/ferrita [12], a presença de boro em solução sólida no aço estudado pode ter estabelecido uma barreira nas interfaces austenita/ferrita reduzindo a reação de formação da ferrita epitaxial ou nova ferrita. Nos trabalhos de Maitrepierre e colaboradores [13] e Asahi [14] foi observada a presença de boro nos contornos de grãos austeníticos durante resfriamento a partir da temperatura de austenitização completa. Conforme os autores $[13,14]$ essa segregação de boro foi responsável pela inibição da nucleação da ferrita nos contornos de grãos.

\section{CONCLUSÃO}

Os resultados via simulação na Gleeble mostraram que a temperatura de encharque (TE) do ciclo completo de recozimento na linha de galvanização por imersão a quente tem influência significativa na microestrutura e, por sua vez, nas propriedades mecânicas do aço bifásico da classe de 980 MPa (DP980).

Observou-se aumento do limite de escoamento (LE) e limite de resistência (LR) com o aumento da TE, o LR apresentou valores superiores a $980 \mathrm{MPa}$ para a TE maior e igual a $750^{\circ} \mathrm{C}$. Já o alongamento total, alongamento uniforme e expoente de encruamento apresentaram tendência de queda com o aumento da TE. O aumento da resistência mecânica e redução da ductilidade foram devidos ao aumento da fração de segundo constituinte (bainita, martensita e MA), variando de $14 \%$ a $54 \%$ para as temperaturas de encharque de $720^{\circ} \mathrm{C}$ e $840^{\circ} \mathrm{C}$, respectivamente.

As diferentes temperaturas de fim de resfriamento lento (TRL) não apresentaram grande influência na microestrutura e nas propriedades mecânicas, fixando a TE em $780^{\circ} \mathrm{C}$. A microestrutura obtida é composta basicamente por ferrita, bainita, 
martensita e constituinte MA. Em todas as temperaturas testadas de fim de resfriamento lento o limite de resistência ficou acima de $980 \mathrm{MPa}$ e a fração volumétrica de segundo constituinte foi em média $44 \%$.

\section{REFERÊNCIAS}

1 Mohanty, R. R., Girina, O. A., Fonstein, N. M. Effect of Heating Rate on the Austenite Formation in Low-Carbon High-Strength Steels Annealed in the Intercritical Region. Metallurgical and Materials Transactions A, v.42A, p.3680-3690, Dec. 2011.

2 Speich, G.R. Physical Metallurgy of Dual-Phase Steels. In: FUNDAMENTALS OF DUAL PHASE STEELS, 1981. The Metallurgical Society of AIME, p.3-45.

3 Lanzillotto, C.A.N., Pickering, F.B. Structure-Property Relationships in Dual-Phase Steels. Metal Science, v.16, p.371-382, August 1982.

4 Lawson, R. D., Matlock, D. K., Krauss, G. The Effect of Microstructure on the Deformation Behavior and Mechanical Properties of a Dual-Phase Steel, In: FUNDAMENTALS OF DUAL PHASE STEELS, 1981. The Metallurgical Society of AIME, p.347-382.

5 Rocha, R. O. Influência de Variáveis de Recozimento Contínuo na Morfologia dos Constituintes de Aços Bifásicos Laminados a Frio da Classe de Limite de Resistência de $600 \mathrm{MPa}$. Belo Horizonte: Universidade Federal de Minas Gerais, 2004. 120p. (Tese, Doutorado em Engenharia Metalúrgica e de Minas).

6 Llewellyn, D. T., Hillis, D. J. Dual Phase Steels - Review. Ironmaking and Steelmaking, v.23, n.6, p.471-478, 1996.

7 Rege, J. S., Inazumi, T., Nagataki, Y., Urabe, T., Smith, G., Zuidema, B., Denner, S. Development of HDGI/HDGA Dual Phase Steel Family (DP500, DP600, DP800, DP1000) at National Steel Corporation. In: MWSP CONFERENCE PROCEEDINGS, 44, v.XL, 2002, p.391-404.

8 Kuang, S., Kang, Y.L., Yu, H., Liu R.D. Effect of Continuous Annealing Parameters on the Mechanical Properties and Microstructures of Cold Rolled Dual Phase Steel. International Journal of Minerals, Metallurgy and Materials, v.16, n.2, p.159-164, April 2009.

9 Cho, K., Garcia, C. I., Shu, H., Chen, T. R., Deardo, A. J. Development of the $590-780$ - $980 \mathrm{Nb}$-Bearing Dual-Phase Steels for Production on Continuous Galvanizing Lines. In: Weng, Y., Dong, H., Gan, Y. Advanced Steels; the recent scenario in steel science and technology. Springer Berlin Heidelberg, 2011. p.313-323

10 Garcia, C. I., Cho, K., Redkin, K., Deardo, A. J., Tan, S., Somani, M., Karjalainen, L. P. Influence of Critical Carbide Dissolution Temperature During Intercritical Annealing on Hardenability of Austenite and Mechanical Properties of DP-980 Steels. ISIJ International, v.51, n.6, p.969-974, Mar. 2011.

11 Pichler, A., Hribernig, G., Tragl, E., Angerer, R., Radlmayr, K., Szinyur, J., Traint, S., Werner, E., Stiaszny, P. Aspects of the Production of Dual Phase and Multiphase Steel Strips. In: MWSP CONFERENCE PROCEEDINGS, 41, v.XXXVII, 1999, p.37-60.

12 Matlock, D.K., Krauss, G., Ramos, L. F., Huppi, G. A. Correlation of Processing Variables with Deformation Behavior of Dual-Phase Steels. New York: TMS-AIME, New York, NY, p.62-90, 1979.

13 Maitrepierre, P., Thivellier, D., Tricot, R. Influence of Boron on the Decomposition of Austenite in Low Carbon Alloyed Steels. Metallurgical Transactions A, v.6A, p.287-301, Fev. 1975.

14 Asahi, H. Effects of Mo Additon and Austenitizing Temperature on Hardenability of Low Alloy B-added Steels. ISIJ International. v.42, p.1150-1155, 2002. 